\title{
Exosome-orchestrated hypoxic tumor microenvironment
}

\author{
Wanrong Meng ${ }^{\dagger}$, Yaying $\mathrm{Hao}^{\dagger}$, Chuanshi He, Ling $\mathrm{Li}^{*}$ and Guiquan Zhu ${ }^{*}$ (D)
}

\begin{abstract}
Hypoxic tumor microenvironment is a common feature of solid tumors and is associated with aggressiveness and poor patient outcomes. A continuous interference between cancer cells and stromal cells within the hypoxic microenvironment has been uncovered for its importance in cancer development and treatment responsiveness. Exosomes, initially considered as "garbage bins" for unwanted material from cells, are now elucidated to perform a variety of functions that involve interactions within the cellular microenvironment due to their ability to carry numerous cargoes, including lipids, proteins, nucleic acids, and metabolites. Exosome-mediated continuous interference between cancer cells and stroma are believed to regulate hypoxia-adaptation and to rebuild the microenvironment in return. In this review, we will discuss the knowledge in literature with respect to the exosome-mediated multi-directional and mutual signal transmission among the variety of cell types within hypoxic cancer microenvironment.
\end{abstract}

Keywords: Hypoxia, Tumor microenvironment, Exosome, Extracellular vesicle, Non-coding RNA, miRNA

\section{Background}

The "seed and soil theory" described by Stephen Paget [1] in the 1880s, for the first time, implied the role of tumor microenvironment (TME) in the initiation and maintenance of tumorigenesis. The TME is an internal physical and chemical condition that cancer cells live in, which is dynamically composed by extracellular matrix (ECM), blood vessels, stromal cells (e.g. immune cells, fibroblasts, endothelial cells, and mesenchymal stem cells), and secreted factors such as cytokines and growth factors [2]. One of the most intensively studied characteristics of TME is hypoxia, defined as a reduction in the normal level of tissue oxygen tension [3, 4]. The hypoxic TME is involved in many "hallmarks of cancer" [5], such as angiogenesis [6], reprogramming energy metabolism [7], evading immune destruction [8], activating invasion and metastasis [9], tumor-promoting inflammation [10], sustaining proliferative signaling [3], resisting cell death [3], and genome instability [7]. As such, hypoxic TME has gained much scientific attention in the past decades.

\footnotetext{
* Correspondence: II@sichuancancer.org; zgq@sichuancancer.org

tWanrong Meng and Yaying Hao contributed equally to this work.

Department of Head and Neck Oncology, Sichuan Cancer Hospital \&

Institute, Sichuan Cancer Center, School of Medicine, University of Electronic

Science and Technology of China, No. 55, Section 4, Renmin South Road,

610041 Chengdu, Sichuan, People's Republic of China
}

Nowadays, there is growing body of new findings to improve the understanding of hypoxia-regulated cancer biology, one of which is the exosome-mediated communications within TME. In this review, we will discuss the knowledge in literature with respect to the exosome-mediated multi-directional and mutual signal transmission among the variety of cell types within hypoxic cancer microenvironment.

\section{Exosomes}

In the past decade, a booming interest has been paid to exosomes in the cancer research, mainly due to the discovery of functional molecular cargos in exosomes that allow them to operate as signaling platforms for information delivery between cells [11].

Exosomes are defined as a class of extracellular vesicles (EVs) formed by inward budding of endosomal membrane and releasing into the extracellular environment upon fusion with the plasma membrane $[12,13]$. Early in 1960s, exosomes (formerly called 'platelet dust') were initially described as subcellular structure originated from normal platelets [14]. The term "exosome" was first described in reticulocytes during the maturation of erythrocytes by Rose M. Johnstone et al. in 1980s [15]. Exosomes have been long-term silenced for

(c) The Author(s). 2019 Open Access This article is distributed under the terms of the Creative Commons Attribution 4.0 International License (http://creativecommons.org/licenses/by/4.0/), which permits unrestricted use, distribution, and 
their presumed role as cellular "garbage dumpsters". This is about to change in 1996, since exosomes derived from B lymphocytes was found to induce antigen-specific MHC-II-restricted $\mathrm{T}$ cell responses, suggesting an active function by exosomes in antigen presentation [16]. Thereafter, an encouraging progress in exosome research has been obtained on many aspects of exosome biology, such as biogenesis and release, morphology, contents, isolation technique, and functions, especially.

\section{Exosome morphology and size}

It has been well documented that exosomes usually appear as cup-shaped under transmission electron microscopy, with a density between 1.13 and $1.17 \mathrm{~g} / \mathrm{ml}$, and expressing CD63, Alix, VPS35, galectin 3, HSP90, fibronectin, and placental alkaline phosphatase [17]. The size of exosomes, however, remains inconclusive, with varied descriptions of $20-100 \mathrm{~nm}$ [18], 30-100 nm [12, 19], $40-100 \mathrm{~nm}$ [20], $30-150 \mathrm{~nm}$ [21], 40-150 nm [11], and $50-100 \mathrm{~nm}$ [17] in different review papers.

We suggest that $30-100 \mathrm{~nm}$ in diameter is the most acceptable description of exosome for several reasons. Firstly, after the initial description of exosomes in reticulocytes with $30-50 \mathrm{~nm}$ of diameter [22], exosomes were then found to be $60-80 \mathrm{~nm}$ from B lymphocytes [16], 60$90 \mathrm{~nm}$ from DCs [23], 40-100 nm from platelets [24], 30$90 \mathrm{~nm}$ from intestinal cells [25], and 60-90 nm from human and mouse tumor cells [26]. With enough respect to the discovery history of exosomes, $30-100 \mathrm{~nm}$ of diameter covers the range of exosome size derived from different cell types. Secondly, vesicles less than $30 \mathrm{~nm}$ in diameter are too small to be observed by photon microscopy [19]. And circulating particles $>100 \mathrm{~nm}$ in size are vulnerable to clearance by the mononuclear phagocyte system [27]. Finally, vesicles $>100 \mathrm{~nm}$ in size represent the morphology of microvesicles that are formed by shedding from cell surface [24]. Therefore a diameter of $30-100 \mathrm{~nm}$ represents a typical range of exosome size in various cell types.

\section{Exosome contents}

In the past decade, studies have revealed that exosomes can carry numerous cargoes, including lipids, proteins, nucleic acids, and metabolites. Exosomal cargos are dependent on the parent cell type and vary between different physiological or pathological conditions in which the donor cells live. Several databases (i.e. ExoCarta [28], EVpedia [29], and Vesiclepedia [30]) have been built up to provide information about exosomal cargos, hosting $>1000$ lipid, > 40,000 proteins, and > 7000 RNAs entries cataloged from 10 different species. Given the large amount of cargos being delivered by exosomes, only a small set of them has their functions revealed in cancer biology, emphasizing the necessity of further investigation.

\section{Hypoxia regulate exosome production}

We and several other groups have provided direct evidence demonstrating an increased production of exosomes in response to hypoxia [31-34] and hypoxia-related conditions such as low $\mathrm{pH}$ [35] and oxidative stress [36]. King et al. [33] exposed breast cancer cell lines to moderate $\left(1 \% \mathrm{O}_{2}\right)$ and severe $\left(0.1 \% \mathrm{O}_{2}\right)$ hypoxia and found a significant increase in exosome number in a hypoxia-inducible factor (HIF)-1 $\alpha$-dependent manner. Wang et al. [32] further demonstrated that HIF-1 $\alpha$ induces exosome release through transactivating the small GTPase RAB22A, which colocalizes with budding vesicles at the surface of breast cancer cells. We showed that oral squamous cell carcinoma (OSCC) cells secreted increased amount of exosomes under hypoxic condition, in which process, HIF- $1 \alpha$ and HIF- $2 \alpha$ played overlapping roles [31]. In keratinocytes, the proline-rich Akt substrate of $40 \mathrm{kDa}$ (PRAS40) was supposed to be required for hypoxia-induced exosome secretion [34].

Other than direct evidences listed above, there are several clues to support the machineries involved in the hypoxia-regulated exosome biogenesis. Firstly, RHO-associated protein kinase (ROCK), an important regulator of actin dynamics, can induce exosome biogenesis in different types of tumor cells [37]. The expression of ROCK [38] has been confirmed to be induced by hypoxia. Secondly, activation of calpain can cause the shedding of micro vesicles from the membrane of aggregating platelets [39]. The mechanism by which calpain regulate exosome biogenesis might be that it drives rearrangements in the asymmetry of membrane phospholipids, which causes physical bending of the membrane and restructuring of the underlying actin cytoskeleton, favoring membrane budding and formation of exosomes [12]. Hypoxia has been suggested to increase mRNA and protein amount of calpain and elicit calpain activation in macrophages [40]. These direct and indirect evidences suggest that exosome production is up-regulated under hypoxic microenvironment, albeit the mechanisms by which still need further clarification.

\section{Hypoxic exosomal biomarkers}

Hypoxia substantially alters the proteomic and nuclear acid profiles of exosomes [31, 41], making them a potential noninvasive biomarker (probe) for hypoxic status of tumors. Studies performed by Kucharzewska et al. [42] with patient materials revealed enrichment in exosomes of hypoxia-regulated mRNAs and proteins (e.g., MMPs, IL-8, PDGFs, caveolin 1, and lysyl oxidase), several of which were associated with poor glioma patient prognosis. They concluded that the proteome and mRNA profiles of exosomes closely reflect the oxygenation status of donor glioma cells and patient tumors and that the exosomal pathway constitutes a potentially targetable 
driver of hypoxia-dependent intercellular signaling during tumor development [42]. In addition, HIF-1 $\alpha$ itself was found in exosomes with transcriptional activity which has been widely accepted as a good biomarker to predict cancer progression as well as treatment outcomes [43]. Consistently, we showed that circulating exosomal miR-21, one of the most significantly upregulated miRNAs under hypoxia, was closely associated with hypoxic status in patients with OSCC [31]. Very recently, an exosome-based platform has been developed to monitor the tumor hypoxia in vivo using magnetic particle imaging [44]. It was showed that hypoxic cells preferentially take up exosomes released by hypoxic donor cells, demonstrating the ability of hypoxic cell-derived exosome as a hypoxia detection probe [44]. Furthermore, this hypoxic exosome-based platform was also efficient in delivering anti-cancer drug and radiosensitizers to various kinds of hypoxic cancers and imaging the efficacy of treatment using magnetic particle imaging [44].

Since hypoxia and expression of hypoxia-related biomarker as associated with cancer progression and treatment responsiveness, various strategies, such as oxygen electrodes, chemical probes, immunohistochemistry, and molecular imaging, have been adopted to assess tumor hypoxia in various cancer types [41]. The exosomal biomarker represents a novel and noninvasive strategy for hypoxia measurement in vivo and for appropriate clinical decision making. However, the identification of tumor specific exosomes in the peripheral blood remains challenging, since they contain mainly overlapping surface markers as non-tumor-derived exosomes.

\section{Tumor derived exosome (TDEs) in hypoxic microenvironment}

The tumor-derived exosomes (TDEs) are enriched in the TME, delivering tumoral signaling to both tumor cells and stromal cells and playing fundamental functions in a wide array of pathological scenarios, such as tumor invasiveness, angiogenesis, proliferation, chemotherapy and radiation resistance, immune evasion, metabolism, and cancer stemness (Fig. 1).

\section{TDE-mediated crosstalk between cancer cells}

The TDE-mediated tumor-tumor cell communications within hypoxic microenvironment have been extensively investigated for their roles in regulating cancer invasiveness and metastasis in nasopharyngeal [43, 45], oral [31], bladder [46], lung [47], prostate [48], breast [32], pancreatic [49], and ovarian [50] carcinomas through carrying a variety of proteins and nuclear acids.

\section{Proteins}

Proteins represent one of the most important exosomal cargos that involved in hypoxia regulation. Aga et al.
[43] found that endogenous HIF-1 $\alpha$ is detectable in nasopharyngeal carcinoma cell-derived exosomes which retains DNA-binding activity and is transcriptionally active in recipient cells after exosome uptake. Exosome-mediated delivery of active forms of HIF- $1 \alpha$ results in reciprocal changes in the expression of E-cadherin and $\mathrm{N}$-cadherin associated with EMT and invasiveness [43]. This is of significant interest, since HIF- $1 \alpha$ is ubiquitinated by Von Hippel Lindau E3 ligase for proteasome degradation in cytoplasm under normoxic condition [51]. Their results indicate that HIF- $1 \alpha$ may keep it safe in exosomes without ubiquitination by Von Hippel Lindau E3 ligase and that exosomal HIF-1 $\alpha$ may be internalized by recipient cells and be translocated to nucleus where transcription factors are supposed to function in.

Several proteins with ECM degradation activity, such as MMP-13 [45], MMP14, and C4.4A [49] have been found in exosomes and been demonstrated to involve in tumor migration and invasiveness. It was showed that hypoxic cancer cells have significantly increased expression of MMP13 in both cellular and exosomal milieu [45]. Exosomal MMP-13 significantly up-regulated Vimentin expression while decreasing E-cadherin levels in recipient cells and contribute to cell invasion in vitro and in vivo [45]. Metastasis-associated C4.4A, being frequently associated with hypoxia, is largely unknown about its function. Ngora et al. [49] found that hypoxia promoted the release of C4.4A in exosomes in a HIF- $1 \alpha$ independent manner. They further demonstrated that hypoxia-induced recruitment of $\alpha 6 \beta 4$ integrin toward exosomal C4.4A, MMP-14 membrane type 1 matrix metalloproteinase/MT1-MMP), and TACE (tumor necrosis factor- $\alpha$-converting enzyme) allows for a shift from adhesion to motility of recipient tumor cells [49]. These results suggest that hypoxic cancer cells could drive non-hypoxic cells toward pro-metastatic phenotype through exosomes that deliver increased mount of ECM degradative proteinases.

Additionally, adhesion molecules [50] and soluble growth factors/cytokines [43] may also be efficiently involved in exosome-mediated recipient cell migration and invasion. The L1 adhesion molecule (CD171) is increased in exosomes under hypoxic condition. Exosomal CD171 from ascites from ovarian carcinoma patients is a potent inducer of cell migration and can trigger extracellular signal-regulated kinase phosphorylation [50]. Soluble factors, such as TGF- $\beta$, TNF- $\alpha$, IL- 6 , and IL-10, are enriched in hypoxic exosomes and are essential for the regulation of recipient cell migration [47, 48]. It has also been revealed that proteins that are involved in exosome biogenesis are required for exosome-mediated cancer progression under hypoxia. The small GTPase, RAB22A for example, is induced by hypoxia dependently on HIF- $1 \alpha$ and plays an important role in hypoxic 


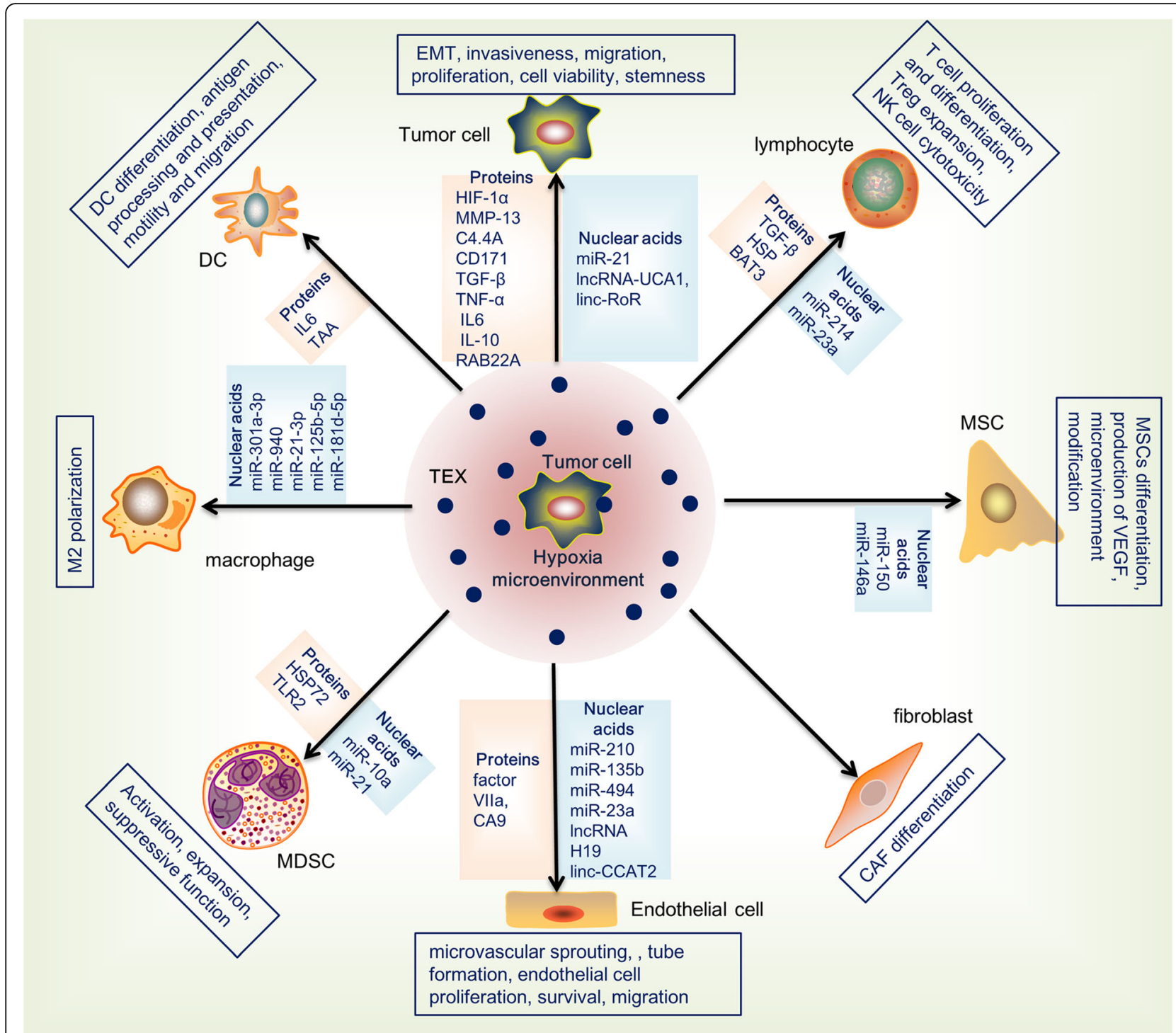

Fig. 1 A schematic representation of hypoxic TDEs in regulating tumor cells and a variety of stromal cells

exosome-induced focal adhesion, invasion, and metastasis of recipient cells [32].

\section{Non-coding RNAs (ncRNAs)}

Another set of exosomal cargos that play key role in hypoxia regulation is ncRNA, miRNAs and lncRNAs especially. We demonstrated in OSCC that hypoxia increases miR-21 levels in TDEs which could be internalized by normoxic cells and elicit recipient cells toward a prometastatic phenotype through regulating the process of epithelial-mesenchymal transition [31]. In addition, lncRNA-UCA1-rich TDEs derived from bladder cancer cells could promote tumor growth and progression though affecting epithelial-mesenchymal transition of recipient bladder cancer cells [46]. However, the molecular mechanism by which exosomal lncRNAs regulate hypoxic adaption remains largely uncovered. This is not surprising, since many genomic regions transcribed into lncRNAs indicated by ENCODE project are supposed to have distinct biological functions, while only a minority of which having been clarified [52].

Other than invasiveness and metastasis, cell proliferation [46], viability [53], and stemness [48] under hypoxic condition have also been suggested to be influenced by TDEs. Hypoxia-induced exosomal lncRNA-UCA1 not only regulates recipient cell invasion, but also contributes to the proliferation of recipient bladder cancer cells [46]. In hepatocellular cancer, exosomal linc-RoR has been suggested to regulate cancer cell viability under hypoxia through a miR-145-HIF-1 $\alpha$ signaling module [53]. Hypoxic TDEs had increased number of proteins (160 proteins) than normoxic TDEs (62 proteins), 
primarily associated with enhanced stemness of prostate cancer cells under hypoxic TME [48]. However, which protein in TDEs is indeed playing the key role in this process has not been elucidated yet. Besides, the mechanisms by which exosomal lncRNA-UCA1 and linc-RoR regulate proliferation and viability respectively remains insufficiently investigated. Hence, though TDEs with protein and ncRNA cargos have been revealed their roles in regulating cell invasiveness, proliferation, viability, and stemness within hypoxic microenvironment, the mechanisms underlying these regulations need further investigation.

\section{TDEs regulate stroma cell biology}

\section{TDEs regulate endothelial cell biology}

Angiogenesis, the growth of new blood vessels from pre-existing ones, is an important process in the cancer development mediated mainly by endothelial cells [21]. It has been widely accepted that hypoxia is a certain driving force of tumor angiogenesis through multiple growth factors and signaling pathways [4]. Recently, TDEs are reported to be enriched in pro-angiogenic proteins which stimulated tubule formation by endothelial cells, not even under hypoxic condition [54]. Given that hypoxia could remarkably rebuild exosomal contents, hypoxic TDE-regulated angiogenesis has gained considerable interest and increasingly evidence has been added to the theoretical framework of hypoxia-induced angiogenesis in the last several years. The potential roles of tumor-derived exosomes in angiogenesis have been recently reviewed by Ludwig et al. [55]. Here, we aim to focus on the hypoxia-related protein and nuclear acid cargos within TDEs that are involved in the regulation of tumor angiogenesis.

\section{Proteins}

Early in 2010, quantitative proteomics performed by Park et al. [56] revealed that hypoxia induced secretion of pro-angiogenic proteins which, unexpectedly, were predominantly cytoplasmic and membrane proteins rather than soluble. By means of ultracentrifugation, $54 \%$ of theses secreted proteins were enriched and many of them were exosome-associated such as CD9 tetraspanins and Alix [56]. Though no functional experiment was performed, this proteomic study provided novel evidence to support the notion that proteins in hypoxic TDEs may potentially regulate angiogenesis. Mattias Beltinga and colleagues showed that microvesicles derived from hypoxic glioblastoma (GBM) cells carry tissue factor and factor VIIa with the potential to activate protease-activated receptor 2, which was found to elicit an angiogenic phenotype of endothelial cells [57]. The same group further demonstrated that exosomes derived from hypoxic GBM cells substantially induced microvascular sprouting compared with normoxic cells [42]. Moreover, exosomes isolated from the plasma of GBM patients in all cases significantly stimulated endothelial cell proliferation and survival [42]. Interestingly, endothelial cells were programmed by GBM cell-derived hypoxic exosomes to secrete several potent growth factors and cytokines and to stimulate pericyte PI3K/AKT signaling activation and migration [42].

Recently, Carbonic anhydrase 9, a validated HIF- $1 \alpha$ target, was identified in renal cell carcinoma cell-derived exosomes and was increased upon hypoxia treatment, which promoted migration and tube formation of human umbilical vein endothelial cells (HUVECs) [58]. These results suggest that hypoxia-induced pro-angiogenic protein may be wrapped in TDEs which, upon infusion, could remold endothelial cell activity and stimulate angiogenesis.

\section{ncRNAs-miRNA}

High throughput techniques (i.e. microarrays and next generation sequencings (NGS) have revealed that miRNAs [59] can be regulated by hypoxia in a variety of cell types. Exosomal miRNAs profiles indeed reflect the changes of parent cells to a certain degree. Using a Taq-Man low-density miRNA array, Tadokoro et al. [60] identified a subset of miRNAs, including miR-210, were significantly increased in exosomes secreted from hypoxic leukemia K562 cells. The increased miR-210 in hypoxic cell-derived exosomes was transferred into HUVECs, which then induced the tubulogenesis of HUVECs under normoxic conditions through targeting Ephrin-A3 [60]. Additionally, hypoxic multiple myeloma (MM) cells are found to produce more exosomes with increased miR-135b levels than the parental cells under normoxia conditions. Exosomal miR-135b directly inhibited its target factor-inhibiting hypoxia-inducible factor 1 (FIH-1) in endothelial cells and thereby enhanced endothelial tube formation [61]. Furthermore, increased miR-494 level in lung cancer cell-derived exosomes was found to target phosphatase and tensin homolog (PTEN) and subsequently activate Akt/eNOS pathway in recipient endothelial cells, resulting in an enhancement of angiogenesis [62]. More recently, hypoxic lung cancer-secreted exosomal miR-23a was found to induce angiogenesis through targeting prolyl hydroxylase 1 and 2, leading to the accumulation of HIF- $1 \alpha$ in endothelial cells; and targeting tight junction protein $\mathrm{ZO}-1$, bringing about increased vascular permeability and cancer trans-endothelial migration [63]. These results suggest that hypoxia-related exosomal miRNA could influence the biology of endothelial cells and induce angiogenesis in several types of cancer through different regulation pathways.

\section{TDE regulate myeloid lineage biology}

Cells of myeloid lineage, including monocytes and neutrophils, macrophages, and DCs, represent a group of 
the most prominent stromal cells in TME [64]. This heterogeneous cell collective plays important roles in tumor immunity, invasion, and progression. Studies by us and several other researchers have showed that hypoxia could redirect the differentiation, induce mobilization and infiltration, and regulate activity of myeloid cells through secretomes by tumor cells, such as growth factors, cytokines, and chemokines [65, 66]. Nowadays, TDEs have made their ways to participate in the regulation of myeloid cell differentiation and function.

\section{Macrophages}

The infiltration of tumor-associated macrophages (TAMs) in the TME is correlated with tumor development. Recently, it was reported that hypoxic pancreatic cancer cells could activate macrophages to the M2 phenotype through delivering miR-301a-3p which activates the PTEN/PI3K $\gamma$ signaling pathway in recipient macrophages [67]. Consistently, Chen et al. [68] found that hypoxia induces the expression of miR-940 in exosomes derived from epithelial ovarian cancer, which stimulated M2 phenotype polarization. The same group further demonstrated that exosomes induced by hypoxia, in comparison with normoxic exosomes, express higher levels of miR-21-3p, miR-125b-5p, and miR-181d-5p, which induce M2 macrophage polarization [69]. The M2 polarization of macrophages induced by hypoxic TDEs could facilitate the migration, invasion, and proliferation of tumor cells in return [67-69]. These results suggest that hypoxic pressure on tumor cell alters the miRNA profiles of TDEs, which could regulate the macrophage differentiation and function on tumor cells in a feedback loop.

\section{Myeloid-derived suppressor cells (MDSCs)}

MDSCs represent a heterogeneous population of immature myeloid cells including immature precursors of DCs, granulocytes, and macrophages [70]. MDSCs are expanded during cancer development and have emerged as critical elements of cancer-induced immune dysfunction, playing multiple roles in tumor progression by promoting tumor cell survival, angiogenesis, invasion, and metastasis [70, 71].

Chalmin et al. [72] demonstrated that mouse TDEs mediated an interaction between tumor cells and MDSCs, which determines the suppressive activity of the MDSC via heat shock protein 72 (Hsp72) triggered Stat3 activation. In the meantime, Xiang et al. [73] showed that exosomes released from in vitro cultured B16 tumor cells are capable of inducing MDSC activation and expansion in a Toll-like receptor 2 (TLR2)-dependent manner. Although discrepancies exist between studies, these results actually suggest that TDEs play important roles in restraining tumor immune surveillance by promoting MDSC suppressive functions [72, 73].
Interestingly, both Hsp72 [74] and TLR2 [75] expression are found to be directly stimulated by hypoxia, indirectly suggesting that hypoxic exosome may regulate the MDSCs function. Direct evidence came through the finding that hypoxia-inducible expression of miR-10a and miR-21 in glioma TDEs mediated TDE-induced MDSC expansion and activation by targeting RAR-related orphan receptor alpha (RORA) and PTEN [71]. These results suggest that hypoxia-induced proteins and miRNAs carried by TDEs may remodel MDSC differentiation and function, which influences tumor progress backward.

\section{TDE regulate lymphocyte biology \\ $T$ cells}

Yin et al. [76] observed that microvesicles derived from mouse sarcoma S-180 cells and Lewis lung carcinoma cells could efficiently transport miR-214 to CD4+ T cells, resulting in a downregulation of PTEN and expansion of Tregs. Although they did not mention the contribution of hypoxia on this regulation, miR-214 is indeed induced by environmental hypoxia [77], suggesting that hypoxia may participate in this regulation process. Another miRNA that can be shuttled to $T$ cells by nasopharyngeal carcinoma cell-derived exosomes is miR-24-3p, which inhibits $T$ cell proliferation and $T_{H} 1$ and $T_{H} 17$ differentiation and induces Treg expansion through targeting fibroblast growth factor 11 in recipient $\mathrm{T}$ cells [78]. This process was found to be enhanced under hypoxia [78]. Exosomal protein cargo, TGF- $\beta$ was found to be delivered to $\mathrm{T}$ cells by breast cancer cell-derived exosomes, which is supposed to mediate the hypoxia-induced loss-of-function of recipient T cells [79]. Other than internalization approach described above, Muller et al. [80] demonstrated that exosomes derived from head and neck squamous cell carcinoma (HNSCC) cells and plasma of patients with HNSCC or acute myelogenous leukemia induced $\mathrm{Ca} 2+$ influx in recipient $\mathrm{T}$ cells by means of surface contact. These results suggest that hypoxia may influence the function of $\mathrm{T}$ cells in TME by miRNAs and proteins delivered by TDEs.

\section{NK cells}

TDEs have been demonstrated to have either stimulatory or inhibitory roles on anti-tumor immune response by NK cells. For instance, TEDs derived from hepatocellular [81], pancreatic [82], and colon [83] carcinoma cells are able to enhance the cytotoxicity of NK cells through transferring proteins such as HSP and HLA-B-associated transcript 3 . However, this stimulation may probably be dysregulated under hypoxic microenvironment. Hypoxia induced a remarkable increase of TGF- $\beta$ in exosomes derived from IGR-Heu (a lung carcinoma cell line) and K562 (a chronic myelogenous leukemia cell line) cells, which inhibited cytotoxicity and IFN- $\gamma$ production by 
NK cells through NKG2D inhibition [84]. Additionally, hypoxia-induced miR-23a in TDEs operated as an additional immunosuppressive factor of NK cells through directly targeting CD107a which is an established marker of NK cell functional activity [84]. These results highlight the role of hypoxia-regulated TDEs on immunodeficiency within TME.

\section{TDEs regulate fibroblast biology}

Fibroblasts are one of the most abundant cell types in the cancer stroma. It was showed that exosomes derived from chronic lymphocytic leukemia (CLL) cells could actively induce a shift of endothelial and bone marrow MSCs toward a cancer-associated fibroblast (CAF) phenotype [85]. Ramteke et al. [48] cultured human prostate cancer cells under hypoxic $\left(1 \% \mathrm{O}_{2}\right)$ or normoxic $\left(21 \% \mathrm{O}_{2}\right)$ conditions, and exosomes isolated from the conditioned media. They showed that hypoxic cancer cell-derived exosomes, compared with paired normoxic ones, remarkably induced the expression of $\alpha$-SMA (an established biomarker for CAFs) expression in recipient prostate fibroblasts, suggesting that hypoxia is involved in the regulation of exosome-mediated CAF differentiation.

\section{TDEs regulate mesenchymal stromal cells (MSCs) biology}

MSCs are a heterogeneous group of progenitor cells with the ability to differentiate into bone, cartilage, adipocytes, fibrocytes, and hematopoietic supporting tissues and are important for tissue regeneration [86]. There are multiple evidences that interactions between tumor cells and MSCs within tumor microenvironment play major roles in supporting cancer progression [87]. Recently, exosomes are found to mediate the crosstalk between tumor cells and MSCs. Paggetti et al. [85] showed that CLL-derived exosomes could shuttle anti-apoptotic proteins, angiogenic factors, and miRNAs (i.e. miR-150 and miR-146a) to MSCs, resulting in a redirection of MSCs differentiation. Intriguingly, HIF- $1 \alpha$ was stimulated and activated in MSCs treated by CLL-derived microvesicles, leading to increased production of vascular endothelial growth factor (VEGF) and modified microenvironment in favor of CLL survival and resistance to chemotherapy [88]. Further investigation is warranted for addressing the direct regulation by hypoxia on TDEs-MSCs interaction in TME.

\section{Stromal cell-derived exosomes in hypoxic microenvironment}

Given that exosomes are secreted by nearly all cell types, exosomes derived from stromal cells could, vice versa, have potential impact on cancer cells and other types of stromal cells in the hypoxic microenvironment (Fig. 2).
Exosomes from stromal cells to tumor cells Macrophage-derived exosomes (MEXs) to tumor cells Macrophages within the TME facilitate angiogenesis and extracellular-matrix breakdown and remodeling and promote tumor cell motility mainly through releasing angiogenic factors, matrix metalloproteases, growth factors, and cytokines [89].

Proteomic study revealed that MEXs, compared with macrophage cell line-derived exosomes, were mainly enriched in RNA processing, proteasome subunits, and ribosomal proteins, indicating that MEXs possessed higher proteolytic activity [90]. Exosomes released by macrophages could deliver miR-223, a miRNA specific for IL-4-activated macrophages, to co-cultured breast cancer cells, eliciting cancer cell invasiveness through targeting Mef2c-b-catenin pathway [91]. In addition, M2 polarized macrophages were found to promote cisplatin resistance in gastric cancer cells through exosomal delivering of miR-21 which suppresses cell apoptosis and enhances activation of PI3K/AKT signaling pathway by down-regulation of PTEN [92]. Moreover, MEXs have been also found to promote the migration of gastric cancer cells by transfer of functional apolipoprotein $\mathrm{E}$ [93]. Intriguingly, miR-223 [94], miR-21 [95], and apolipoprotein E [96] have been reported to be negatively or positively regulated by hypoxia/HIF-1 $\alpha$ in several cell types. However, it remains unidentified whether this regulation exists in TAMs within hypoxic TME and whether hypoxia- regulated miR-223, miR-21, and apolipoprotein $\mathrm{E}$ could affect the exosome-mediated cancer invasiveness.

\section{NK cell-derived exosomes (NK-Exos) to tumor cells}

It has been shown that NK-Exos not only express both typical NK markers (i.e., CD56) and killer proteins (i.e., FASL and perforin) but also exert antitumor and immune homeostatic activities [97, 98]. NK-Exos are found to secrete TNF- $\alpha$ which affected the cell proliferation signaling pathway and exert cytotoxic activity against different human tumor target cells $[98,99]$.

These profiles of NK-Exos warrant them an attractive therapeutic candidate for cancer. In TME, particularly hypoxic milieu, the NK cell activation and cytotoxicity are impaired by multiple mechanisms [100]. Although hypoxia did not alter surface expression of NK cell ligands (HLA-ABC, MICA/B, and ULBP1-2) and receptors (KIR, NKG2A/C, DNAM-1, NCRs and 2B4), it did decrease the expression of the activating NKG2D receptor and intracellular perforin and granzyme B [101]. In fact, the role of NKG2D is now emerging in the control of tumorigenesis, supported by the upregulation of NKG2D ligands in tumor cells [99]. Thus, hypoxia is found to reduce NK cell killing of MM cell in an oxygen dependent manner [101]. However, there is no direct evidence so far linking hypoxia and the 


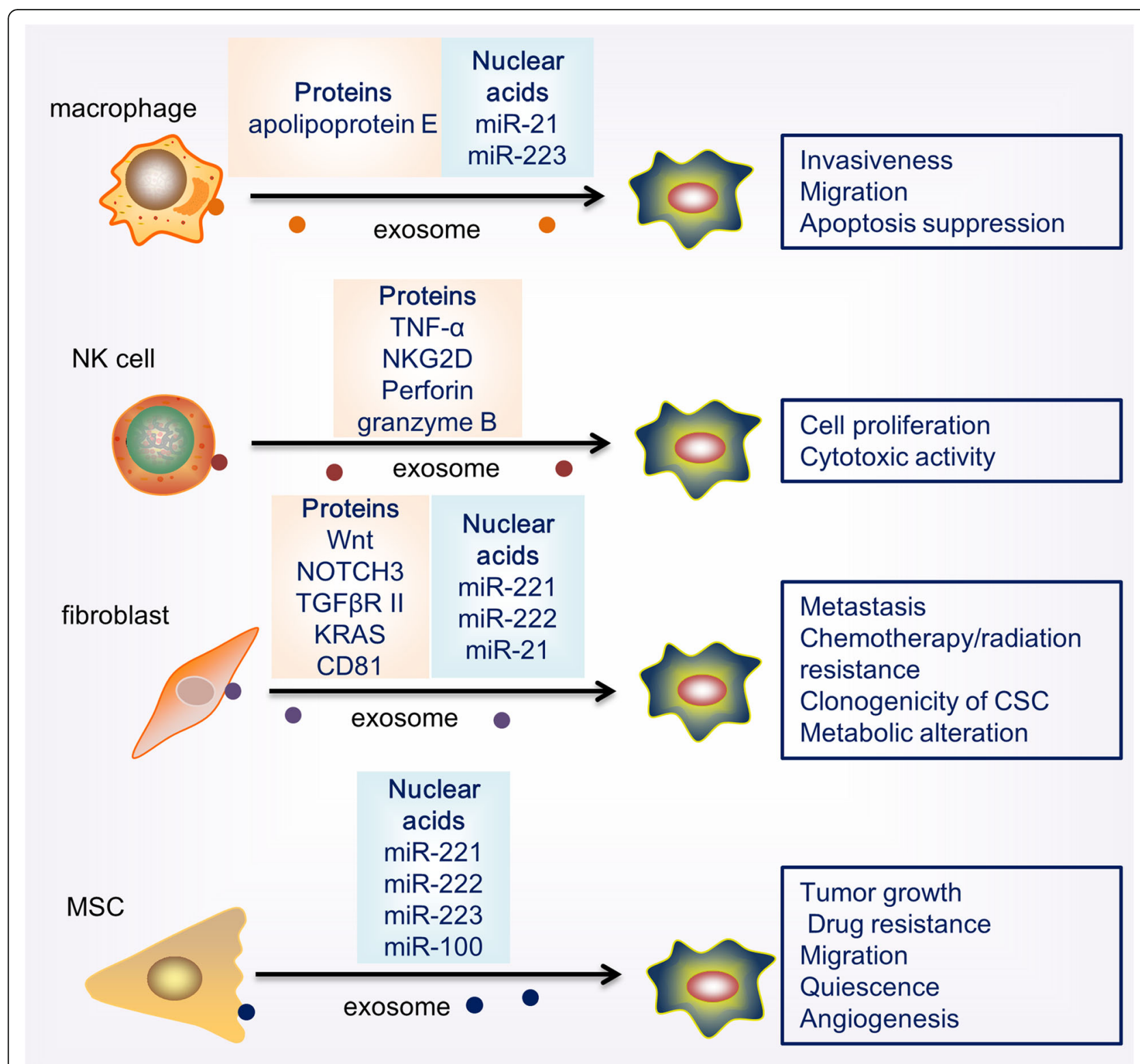

Fig. 2 A schematic representation of stromal cell-derived exosomes on cancer cell function in hypoxic TME

cytotoxicity of NK-Exos, which is fundamentally important for NK-Exo-based cancer therapy and needs further investigation.

\section{Fibroblast-derived exosomes to tumor cells}

Hypoxic cancer cells promote an activation of CAF which, in turn, are able to support angiogenesis as well as cancer cells invasiveness, stemness, chemoresistance, and immune cells recruitment in the TME [102]. Zhao et al. [103] found that CAF-derived exosomes could be taken up by cancer cells in a KRAS-independent manner and are capable of inhibiting mitochondrial oxidative phosphorylation, thereby increasing glycolysis and glutamine-dependent reductive carboxylation in cancer cells. Interestingly, reductive carboxylation is a critical pathway to support the growth of tumor cells under hypoxia. These results, indeed, suggest that CAF-derived exosomes could induce metabolic alterations in cancer cells via mimicking hypoxia- induced environment [103]. Functional studies performed by Au Yeung et al. [104] showed that miR-21 is transferred from CAFs to the cancer cells, where it suppresses ovarian cancer apoptosis and confers chemoresistance by binding to its direct novel target, APAF1.

Since miR-21 is increased under hypoxia in a HIF- $1 \alpha$ dependent manner [95], this results suggest an potential involvement of hypoxia in CAF-derived exosome-mediated cancer progression. Thus far, there still lack direct evidence 
to demonstrate whether hypoxia could modify the profile and function of CAF-derived exosomes in TME. Proteomic analysis performed on cardiac fibroblasts revealed that hypoxia selectively increase expression of proteins with ECM and signaling annotations in cardiac fibroblast-derived exosomes [105]. This could be an indication that hypoxic TME may be able to modify the CAF-derived exosomal cargo and function, which needs further investigation though.

\section{MSC-derived exosomes (MSC-Exos) to tumor cells}

MSCs from gastric cancer tissues could favor cancer growth and migration by transferring exosomal miR-221 to cancer cells [106]. Additionally, MM-derived MSCs secret exosomes, with a lower content of the tumor suppressor miR-15a and higher levels of oncogenic proteins, cytokines, and adhesion molecules, could promote MM tumor growth [107]. Moreover, Bliss et al. [108] reported that breast cancer cells prime MSCs to release exosomes containing miR-222/223, which in turn promotes quiescence in a subset of cancer cells and confers drug resistance. They found that systemic administration of MSC loaded with antagomiR-222/223 sensitized breast cancer cells to carboplatin-based therapy and increased host survival [108]. Recently, it was showed that MSC-derived exosomes with miR-100 cargo could modulate mTOR/ HIF- $1 \alpha$ signaling axis in recipient breast cancer cells, resulting in a decrease in VEGF expression [109]. These results support the notion that exosome-mediated mutual signaling exchange between MSCs and cancer cells mediates cancer progress and hypoxia signaling is involved in. The role of MSC-derived exosomes in stromal remodeling, tumor progression, and cancer immunotherapy has been intensively reviewed by Farah Fatima and Muhammad Nawaz [110]. However, no direct evidence on the role of hypoxia on MSC-derived exosome function has been revealed yet.

Hitherto, there is limited evidence on the direct regulation by hypoxia on stromal cell-derived exosome secretion and content profiles, as well as their function on cancer cell biology. Since exosomes derived from T lymphocytes [20], DCs [111], and NK [97] cells exhibit characteristics and functions from their parent cells, exosomes derived from these cells are now being considered potential candidates for cancer therapy. Whether the distribution and uptake of these exosomes by cancer cell would be modified under hypoxic microenvironment remains largely unknown, which is presumably a critical step for exosome-based therapy. In addition, whether hypoxia could affect stromal cell-derived exosome production as well as content profiles is underinvestigated so far. In the future, it is interesting to know more about the role of hypoxia on stromal cell-derived exosome function, which is a critical branch of the bidirectional signaling transfer by exosomes between cancer cells and stromal cells within hypoxic TME.
Exosomes from stromal cells to stromal cells

The general involvement of exosomes in intercellular communication suggests that they may contribute to the exchange of biological information within stromal elements, which may mobilize and re-localize the oncogenic factors as well as immune cells that shape the tumor environment [110].

\section{DC-derived exosomes (DEXs) to stromal cells}

Exosomes derived from DCs have been well documented to inherit the antigen-presenting profile from their parent cells. Thus DEXs can modulate recipient cells in a manner beyond classical ligand/receptor signaling pathways, which creates complex cellular modifications that may play substantial roles in tumor development and immune responses [111]. DEXs could be taken up by NK cells, T lymphocytes, and DCs as well and thereby modulate the recipient cell function.

DCs at different stages of maturation release exosomes with different miRNA content [112] as well as MHC I/II class/peptide complexes [11]. These bioactive contents could be delivered to NK cells, T lymphocytes, and DCs as well upon internalization, hemifusion, and fusion with the recipient cells.

It was demonstrated that DEXs express functional IL-15R $\alpha$ and NKG2D ligands, which promoted recipient NK cell [113] and CD8+ T cell [114] proliferation and activation. However, the regulatory effect of hypoxia on DCs in the TME has not been well clarified yet. Available literature suggests that hypoxia may favor the ability of DCs to induce immune responses, due to the fact that hypoxic DCs have up-regulated expression of pattern recognition receptors (e.g. CD180), components of complement receptor (e.g. Toll-like receptor-1/2 and C-type lectin receptors), and immunoregulatory receptors (e.g. immunoglobulin-Fc receptors) [115]. However, effect of hypoxia on the biogenesis, production, contents, and antigen-presenting functions of DEXs remains underinvestigated, which might be an attractive topic in the future.

\section{Macrophage-derived exosomes to stromal cells}

We mentioned above that exosomes released by macrophages could deliver miR-223 to co-cultured cancer cells to elicit an invasive phenotype of breast cancer [91]. These miR-223 containing MEXs could also be transported to stromal cells, including monocytes, endothelial cells, epithelial cells, and fibroblasts [116]. miR-223 delivered by exosomes derived from activated macrophages induce the differentiation of recruited monocytes toward macrophages [116]. Recently Cheng et al. demonstrated that exosomes derived from M1-polarized, proinflammatory macrophages displayed a tropism toward lymph nodes after subcutaneous injection, primarily taken up by the local macrophages and DCs, and they induced 
the release of a pool of Th1 cytokines [117]. Interestingly, M1, but not M2, exosomes induced a stronger antigen-specific cytotoxic T cell response [117]. Though, they did not dig into the molecular mechanisms underlying the MEX-induced vaccination and $T$ cell response. Hypoxia may potentially participate in the MEX-regulated macrophage differentiation as well as $\mathrm{T}$ cell response, because elevated HIF- $1 \alpha$ has been shown to trigger a decrease of miR-223 in pulmonary artery smooth muscle cells [94]. If this HIF-1 $\alpha$-dependent downregulation of miR-223 exists in macrophages, MEX-regulated macrophage differentiation and $\mathrm{T}$ cell response may be negatively influenced in hypoxic TME.

\section{MDSC-derived exosome (MDSC-Exo) to stromal cells}

Mass spectrometry and RNA-sequencing showed that MDSC-Exos carry proteins, mRNAs, and microRNAs, some of which have known or predicted functions consistent with MDSC suppressive activity [118]. Functional study showed that MDSC-Exos are taken up by $\mathrm{T}$ cells, macrophages, and NK cells, resulting in a strong increase in Treg, reduced $\mathrm{T}$ helper proliferation, mitigated cytotoxic activity, and slight increase in lymphocyte apoptosis [119]. However, in this study, the molecular mechanism underlying the MDSC-Exo-mediated immunosuppression was not investigated. Deng et al. [120] found that doxorubicin-treated $4 \mathrm{~T} 1$ breast tumor bearing mice had an increase of miR-126 + MDSCs which produce miR-126a-rich exosomes. The miR-126-rich MDSC-Exos, upon transferred to $\mathrm{T}$ cells, significantly suppressed Th1 cell proliferation and IFN- $\gamma$ secretion and induced Th2 cell responses. These effects finally contributed to tumor angiogenesis, lung metastasis, and chemo resistance [120]. We and other researchers have shown that hypoxia, mainly through HIF- $1 \alpha$, indeed regulate MDSC recruitment [65], differentiation [121], and immunosuppressive function [122]. However, no study yet, to the best of our knowledge, has reported the direct role of hypoxia on MDSC-Exo production, exosomal content profile, or immunoregulatory function. Since miR-126 was found to inhibit HIF- $1 \alpha$ protein expression and miR-126 deactivation induced a pseudohypoxia in renal cell carcinoma model [123], it indicates a potential correlation between hypoxia and miR-126+ MDSC-Exo-mediated immunosuppression.

\section{Conclusions}

Cancer cells and stromal cells within TME are influenced by the physical and chemical milieu, and crosstalk between cells may also dynamically reshape the microenvironment in a feedback manner. Exosomes, science being discovered as a signaling carrier and communication media, have waved themselves the forefront of cancer research in the last decade. In hypoxic microenvironment, the production of exosomes as well as exosomal protein and nuclear acid profiles may be influenced by the shortage of oxygen and the acid circumstance, which makes exosome a potential noninvasive approach for diagnosis of tumors with hypoxia. Indeed, the application of exosomes as a minimally-invasive circulating biomarker platform has gained much attention and is under intensive investigation.

Exosomes mediate a broad range of bidirectional signal transductions between a variety of cell types (cancer cell-cancer cell, cancer cell-stromal cell, and stromal cell-stromal cell) within hypoxic TME, playing essential roles in tumor invasiveness, angiogenesis, proliferation, chemotherapy and radiation resistance, immune evasion, metabolism, and cancer stemness. Exosomes derived from tumor cells have been widely invested for their roles in regulating the biology of recipient tumor cells and diverse stromal cells in hypoxic TME. The stromal cell-derived exosomes, however, remains underinvestigated for their roles in the regulation of hypoxic TME, which is undeniably significant in the dynamics of hypoxic TME and cancer progression. Given that exosomes derived from $\mathrm{T}$ cells, DCs, and NK cells exhibit both anti-tumor effects and immunoregulatory functions, the potential use of exosome as an immunotherapy reagent or as a drug delivery platform has obtained considerable scientific interest. However, the production, infiltration, distribution, and incorporation of the stromal cell-derived exosomes under hypoxic conditions are of significant importance for exosome-based therapeutics and far from well elucidated yet. A more comprehensive understanding of exosomes and their molecular cargos, stromal origin especially, in the regulation of hypoxic TME is challenging and fascinating for the improvement of detection and treatment of hypoxic tumors in the future.

\section{Abbreviations}

CAF: Cancer-associated fibroblast; CLL: Lymphocytic leukemia; DC: Dendritic cell; DEX: DC-derived exosome; ECM: Extracellular matrix; EMT: Epithelial to mesenchymal transition; ENCODE: Encyclopedia of DNA Elements; EV: Extracellular vesicle; FASL: Fas ligand; FIH-1: Factor-inhibiting hypoxiainducible factor 1; GBM: Glioblastoma; HIF: Hypoxia-inducible factor; HLA: Human leukocyte antigen; HNSCC: Head and neck squamous cell carcinoma; Hsp72: Heat shock protein 72; HUVEC: Human umbilical vein endothelial cells; KIR: Killer-cell immunoglobulin-like receptor; MDSC: Myeloid-derived suppressor cell; MDSC-Exo: MDSC-derived exosome; MEX: Macrophage-derived exosome; MHC: Major histocompatibility complex; MICA: MHC class I polypeptide-related sequence A; miRNA: microRNA; MM: Multiple myeloma; MMP: Matrix metalloproteinase; MSC: Mesenchymal stromal cell; MSC-Exo: MSC-derived exosome; NCR: Natural cytotoxicity receptor; ncRNA: Non-coding RNA; NGS: Next generation sequencings; NK: Natural killer cell; NK-Exo: NK cell-derived exosome; OSCC: Oral squamous cell carcinoma; PDGF: Platelet-derived growth factor; PRAS40: Proline-rich Akt substrate of $40 \mathrm{kDa}$; PTEN: Phosphatase and tensin homolog; ROCK: RHOassociated protein kinase; RORA: RAR-related orphan receptor alpha;

TACE: Tumor necrosis factor-a-converting enzyme; TAM: Tumor-associated macrophage; TDE: Tumor derived exosome; TGF- $\beta$ : Transforming growth factor beta; TLR2: Toll-like receptor 2; TME: Tumor microenvironment; TNFa: Tumor necrosis factor alpha; Treg: Regulatory T cell; ULBP1: UL16 binding protein 1; VEGF: Vascular endothelial growth factor 


\section{Acknowledgements}

We thank Dr. Bangrong Cao for sophisticated reviewing and kind suggestion.

\section{Funding}

This work was supported by the National Natural Science Foundation of China (grant No. 81872196, 81772900, and 81672690) and the Department of Science and Technology of Sichuan Province (grant No. 2018JY0646 and 2017JQ0040).

\section{Availability of data and materials} Not applicable.

\section{Authors' contributions}

WM and $\mathrm{YH}$ collected the related paper and drafted this review; $\mathrm{CH}$ prepared the figures; $L L$ and $G Z$ edited and revised the manuscript; $G Z$ made critical revisions and proofread the manuscript. All authors read and approved the final manuscript.

\section{Ethics approval and consent to participate}

Not applicable.

\section{Consent for publication}

The authors have consented to publish this article.

\section{Competing interests}

The authors declare that they have no competing interests.

\section{Publisher's Note}

Springer Nature remains neutral with regard to jurisdictional claims in published maps and institutional affiliations.

\section{Received: 2 December 2018 Accepted: 25 February 2019} Published online: 30 March 2019

\section{References}

1. Paget $\mathrm{S}$. The distribution of secondary growths in cancer of the breast 1889. Cancer Metastasis Rev. 1989;8:98-101.

2. Casey SC, Amedei A, Aquilano K, Azmi AS, Benencia F, Bhakta D, Bilsland AE, Boosani CS, Chen S, Ciriolo MR, et al. Cancer prevention and therapy through the modulation of the tumor microenvironment. Semin Cancer Biol. 2015;35(Suppl):S199-s223.

3. Harris AL. Hypoxia--a key regulatory factor in tumour growth. Nat Rev Cancer. 2002;2:38-47.

4. Brahimi-Horn MC, Chiche J, Pouyssegur J. Hypoxia and cancer. J Mol Med. 2007:85:1301-7

5. Hanahan D, Weinberg RA. Hallmarks of cancer: the next generation. Cell. 2011;144:646-74

6. Jain RK. Antiangiogenesis strategies revisited: from starving tumors to alleviating hypoxia. Cancer Cell. 2014;26:605-22.

7. Bristow RG, Hill RP. Hypoxia and metabolism. Hypoxia, DNA repair and genetic instability. Nat Rev Cancer. 2008;8:180-92.

8. Palazon A, Goldrath AW, Nizet V, Johnson RS. HIF transcription factors, inflammation, and immunity. Immunity. 2014;41:518-28.

9. Rankin EB, Giaccia AJ. Hypoxic control of metastasis. Science. 2016:352:175-80.

10. Peng G, Liu Y. Hypoxia-inducible factors in cancer stem cells and inflammation. Trends Pharmacol Sci. 2015:36:374-83.

11. Ruivo CF, Adem B, Silva M, Melo SA. The biology of cancer exosomes: insights and new perspectives. Cancer Res. 2017:77:6480-8.

12. van Niel G, D'Angelo G, Raposo G. Shedding light on the cell biology of extracellular vesicles. Nat Rev Mol Cell Biol. 2018.

13. Liu Y, Gu Y, Cao X. The exosomes in tumor immunity. Oncoimmunology. 2015:4:e1027472

14. Wolf $P$. The nature and significance of platelet products in human plasma. Br J Haematol. 1967;13:269-88.

15. Johnstone RM, Adam M, Hammond JR, Orr L, Turbide C. Vesicle formation during reticulocyte maturation. Association of plasma membrane activities with released vesicles (exosomes). J Biol Chem. 1987;262:9412-20.

16. Raposo G, Nijman HW, Stoorvogel W, Liejendekker R, Harding CV, Melief CJ, Geuze HJ. B lymphocytes secrete antigen-presenting vesicles. J Exp Med. 1996;183:1161-72
17. Taylor DD, Gercel-Taylor C. Exosomes/microvesicles: mediators of cancerassociated immunosuppressive microenvironments. Semin Immunopathol. 2011;33:441-54

18. Dorayappan KDP, Wallbillich JJ, Cohn DE, Selvendiran K. The biological significance and clinical applications of exosomes in ovarian cancer. Gynecol Oncol. 2016;142:199-205.

19. Thery C, Zitvogel L, Amigorena S. Exosomes: composition, biogenesis and function. Nat Rev Immunol. 2002;2:569-79.

20. Ventimiglia LN, Alonso MA. Biogenesis and function of $T$ cell-derived exosomes. Front Cell Dev Biol. 2016:4:84.

21. Salem KZ, Moschetta M, Sacco A, Imberti L, Rossi G, Ghobrial IM, Manier S, Roccaro AM. Exosomes in tumor angiogenesis. Methods Mol Biol. 2016; 1464:25-34

22. Pan BT, Teng K, Wu C, Adam M, Johnstone RM. Electron microscopic evidence for externalization of the transferrin receptor in vesicular form in sheep reticulocytes. J Cell Biol. 1985;101:942-8.

23. Zitvogel L, Regnault A, Lozier A, Wolfers J, Flament C, Tenza D, RicciardiCastagnoli P, Raposo G, Amigorena S. Eradication of established murine tumors using a novel cell-free vaccine: dendritic cell-derived exosomes. Nat Med. 1998:4:594-600.

24. Heijnen HF, Schiel AE, Fijnheer R, Geuze HJ, Sixma JJ. Activated platelets release two types of membrane vesicles: microvesicles by surface shedding and exosomes derived from exocytosis of multivesicular bodies and alphagranules. Blood. 1999;94:3791-9.

25. van Niel G, Raposo G, Candalh C, Boussac M, Hershberg R, Cerf-Bensussan $\mathrm{N}$, Heyman M. Intestinal epithelial cells secrete exosome-like vesicles. Gastroenterology. 2001;121:337-49.

26. Wolfers J, Lozier A, Raposo G, Regnault A, Thery C, Masurier C, Flament C, Pouzieux S, Faure F, Tursz T, et al. Tumor-derived exosomes are a source of shared tumor rejection antigens for CTL cross-priming. Nat Med. 2001;7:297-303.

27. van den Boorn JG, Dassler J, Coch C, Schlee M, Hartmann G. Exosomes as nucleic acid nanocarriers. Adv Drug Deliv Rev. 2013:65:331-5.

28. Keerthikumar S, Chisanga D, Ariyaratne D, Al Saffar H, Anand S, Zhao K, Samuel M, Pathan M, Jois M, Chilamkurti N, et al. ExoCarta: a web-based compendium of Exosomal cargo. J Mol Biol. 2016;428:688-92.

29. Kim DK, Lee J, Simpson RJ, Lotvall J, Gho YS. EVpedia: a community web resource for prokaryotic and eukaryotic extracellular vesicles research. Semin Cell Dev Biol. 2015:40:4-7.

30. Kalra H, Simpson RJ, Ji H, Aikawa E, Altevogt P, Askenase P, Bond VC, Borras FE, Breakefield X, Budnik $V$, et al. Vesiclepedia: a compendium for extracellular vesicles with continuous community annotation. PLoS Biol. 2012;10:e1001450.

31. Li L, Li C, Wang S, Wang Z, Jiang J, Wang W, Li X, Chen J, Liu K, Li C, Zhu G. Exosomes derived from hypoxic Oral squamous cell carcinoma cells deliver miR-21 to normoxic cells to elicit a Prometastatic phenotype. Cancer Res. 2016;76:1770-80.

32. Wang T, Gilkes DM, Takano N, Xiang L, Luo W, Bishop CJ, Chaturvedi P, Green JJ, Semenza GL. Hypoxia-inducible factors and RAB22A mediate formation of microvesicles that stimulate breast cancer invasion and metastasis. Proc Natl Acad Sci U S A. 2014;111:E3234-42.

33. King HW, Michael MZ, Gleadle JM. Hypoxic enhancement of exosome release by breast cancer cells. BMC Cancer. 2012;12:421.

34. Guo J, Jayaprakash P, Dan J, Wise P, Jang GB, Liang C, Chen M, Woodley DT, Fabbri M, Li W. PRAS40 connects microenvironmental stress signaling to exosome-mediated secretion. Mol Cell Biol. 2017:37.

35. Parolini I, Federici C, Raggi C, Lugini L, Palleschi S, De Milito A, Coscia C, lessi E, Logozzi M, Molinari A, et al. Microenvironmental pH is a key factor for exosome traffic in tumor cells. J Biol Chem. 2009;284:34211-22.

36. Hedlund M, Nagaeva O, Kargl D, Baranov V, Mincheva-Nilsson L. Thermaland oxidative stress causes enhanced release of NKG2D ligand-bearing immunosuppressive exosomes in leukemia/lymphoma T and B cells. PLoS One. 2011:6:e16899.

37. Li B, Antonyak MA, Zhang J, Cerione RA. RhoA triggers a specific signaling pathway that generates transforming microvesicles in cancer cells. Oncogene. 2012;31:4740-9.

38. Wang Z, Jin N, Ganguli S, Swartz DR, Li L, Rhoades RA. Rho-kinase activation is involved in hypoxia-induced pulmonary vasoconstriction. Am J Respir Cell Mol Biol. 2001:25:628-35.

39. Pasquet JM, Toti F, Nurden AT, Dachary-Prigent J. Procoagulant activity and active calpain in platelet-derived microparticles. Thromb Res. 1996;82: $509-22$. 
40. Cui W, Zhou J, Dehne N, Brune B. Hypoxia induces calpain activity and degrades SMAD2 to attenuate TGFbeta signaling in macrophages. Cell Biosci. 2015:5:36.

41. Thomas SN, Liao Z, Clark D, Chen Y, Samadani R, Mao L, Ann DK, Baulch JE, Shapiro P, Yang AJ. Exosomal proteome profiling: a potential multi-marker cellular phenotyping tool to characterize hypoxia-induced radiation resistance in breast cancer. Proteomes. 2013;1:87-108.

42. Kucharzewska P, Christianson HC, Welch JE, Svensson KJ, Fredlund E, Ringner M, Morgelin M, Bourseau-Guilmain E, Bengzon J, Belting M. Exosomes reflect the hypoxic status of glioma cells and mediate hypoxiadependent activation of vascular cells during tumor development. Proc Natl Acad Sci U S A. 2013;110:7312-7.

43. Aga M, Bentz GL, Raffa S, Torrisi MR, Kondo S, Wakisaka N, Yoshizaki T, Pagano JS, Shackelford J. Exosomal HIF1alpha supports invasive potential of nasopharyngeal carcinoma-associated LMP1-positive exosomes. Oncogene. 2014;33:4613-22

44. Jung KO, Jo H, Yu JH, Gambhir SS, Pratx G. Development and MPI tracking of novel hypoxia-targeted theranostic exosomes. Biomaterials. 2018;177:139-48.

45. Shan Y, You B, Shi S, Shi W, Zhang Z, Zhang Q, Gu M, Chen J, Bao L, Liu D, You Y. Hypoxia-induced matrix Metalloproteinase-13 expression in exosomes from nasopharyngeal carcinoma enhances metastases. Cell Death Dis. 2018;9:382.

46. Xue M, Chen W, Xiang A, Wang R, Chen H, Pan J, Pang H, An H, Wang X, Hou H, Li X. Hypoxic exosomes facilitate bladder tumor growth and development through transferring long non-coding RNA-UCA1. Mol Cancer. 2017;16:143.

47. Wang Y, Yi J, Chen X, Zhang Y, Xu M, Yang Z. The regulation of cancer cel migration by lung cancer cell-derived exosomes through TGF-beta and IL10. Oncol Lett. 2016;11:1527-30.

48. Ramteke A, Ting H, Agarwal C, Mateen S, Somasagara R, Hussain A, Graner M, Frederick B, Agarwal R, Deep G. Exosomes secreted under hypoxia enhance invasiveness and stemness of prostate cancer cells by targeting adherens junction molecules. Mol Carcinog. 2015:54:554-65.

49. Ngora H, Galli UM, Miyazaki K, Zoller M. Membrane-bound and exosomal metastasis-associated (4.4A promotes migration by associating with the alpha (6) beta (4) integrin and MT1-MMP. Neoplasia. 2012;14:95-107.

50. Gutwein $P$, Stoeck A, Riedle S, Gast D, Runz S, Condon TP, Marme A, Phong MC, Linderkamp O, Skorokhod A, Altevogt P. Cleavage of L1 in exosomes and apoptotic membrane vesicles released from ovarian carcinoma cells. Clin Cancer Res. 2005;11:2492-501.

51. Semenza GL. Hypoxia-inducible factors: coupling glucose metabolism and redox regulation with induction of the breast cancer stem cell phenotype. EMBO J. 2017:36:252-9.

52. Gutschner T, Diederichs $\mathrm{S}$. The hallmarks of cancer: a long non-coding RNA point of view. RNA Biol. 2012;9:703-19.

53. Takahashi K, Yan IK, Haga H, Patel T. Modulation of hypoxia-signaling pathways by extracellular linc-RoR. J Cell Sci. 2014;127:1585-94.

54. Skog J, Wurdinger T, van Rijn S, Meijer DH, Gainche L, Sena-Esteves M, Curry WT Jr, Carter BS, Krichevsky AM, Breakefield XO. Glioblastoma microvesicles transport RNA and proteins that promote tumour growth and provide diagnostic biomarkers. Nat Cell Biol. 2008;10:1470-6.

55. Ludwig N, Whiteside TL. Potential roles of tumor-derived exosomes in angiogenesis. Expert Opin Ther Targets. 2018;22:409-17.

56. Park JE, Tan HS, Datta A, Lai RC, Zhang H, Meng W, Lim SK, Sze SK. Hypoxic tumor cell modulates its microenvironment to enhance angiogenic and metastatic potential by secretion of proteins and exosomes. Mol Cell Proteomics. 2010;9:1085-99.

57. Svensson KJ, Kucharzewska P, Christianson HC, Skold S, Lofstedt T, Johansson MC, Morgelin M, Bengzon J, Ruf W, Belting M. Hypoxia triggers a proangiogenic pathway involving cancer cell microvesicles and PAR-2mediated heparin-binding EGF signaling in endothelial cells. Proc Natl Acad Sci U S A. 2011;108:13147-52.

58. Horie K, Kawakami K, Fujita Y, Sugaya M, Kameyama K, Mizutani K, Deguchi T, Ito M. Exosomes expressing carbonic anhydrase 9 promote angiogenesis. Biochem Biophys Res Commun. 2017:492:356-61.

59. Voellenkle C, Rooij J, Guffanti A, Brini E, Fasanaro P, Isaia E, Croft L, David M, Capogrossi MC, Moles A, et al. Deep-sequencing of endothelial cells exposed to hypoxia reveals the complexity of known and novel microRNAs. Rna. 2012;18:472-84.

60. Tadokoro H, Umezu T, Ohyashiki K, Hirano T, Ohyashiki JH. Exosomes derived from hypoxic leukemia cells enhance tube formation in endothelial cells. J Biol Chem. 2013;288:34343-51.
61. Umezu T, Tadokoro H, Azuma K, Yoshizawa S, Ohyashiki K, Ohyashiki JH. Exosomal miR-135b shed from hypoxic multiple myeloma cells enhances angiogenesis by targeting factor-inhibiting HIF-1. Blood. 2014;124:3748-57.

62. Mao G, Liu Y, Fang X, Liu Y, Fang L, Lin L, Liu X, Wang N. Tumor-derived microRNA-494 promotes angiogenesis in non-small cell lung cancer. Angiogenesis. 2015;18:373-82.

63. Hsu YL, Hung JY, Chang WA, Lin YS, Pan YC, Tsai PH, Wu CY, Kuo PL. Hypoxic lung cancer-secreted exosomal miR-23a increased angiogenesis and vascular permeability by targeting prolyl hydroxylase and tight junction protein ZO-1. Oncogene. 2017;36:4929-42.

64. Broz ML, Krummel MF. The emerging understanding of myeloid cells as partners and targets in tumor rejection. Cancer Immunol Res. 2015:3:313-9.

65. Zhu G, Tang Y, Geng N, Zheng M, Jiang J, Li L, Li K, Lei Z, Chen W, Fan Y, et al. HIF-alpha/MIF and NF-kappaB/IL-6 axes contribute to the recruitment of CD11b+Gr-1+ myeloid cells in hypoxic microenvironment of HNSCC. Neoplasia. 2014;16:168-79.

66. Corzo CA, Condamine T, Lu L, Cotter MJ, Youn Jl, Cheng P, Cho HI, Celis E, Quiceno DG, Padhya T, et al. HIF-1alpha regulates function and differentiation of myeloid-derived suppressor cells in the tumor microenvironment. J Exp Med. 2010;207:2439-53.

67. Wang X, Luo G, Zhang K, Cao J, Huang C, Jiang T, Liu B, Su L, Qiu Z. Hypoxic tumor-derived exosomal miR-301a mediates M2 macrophage polarization via PTEN/PI3Kgamma to promote pancreatic cancer metastasis. Cancer Res. 2018;78:4586-98

68. Chen X, Ying X, Wang X, Wu X, Zhu Q, Wang X. Exosomes derived from hypoxic epithelial ovarian cancer deliver microRNA-940 to induce macrophage M2 polarization. Oncol Rep. 2017;38:522-8.

69. Chen $X$, Zhou J, Li X, Wang $X$, Lin $Y$, Wang $X$. Exosomes derived from hypoxic epithelial ovarian cancer cells deliver microRNAs to macrophages and elicit a tumor-promoted phenotype. Cancer Lett. 2018;435:80-91.

70. Obermajer N, Muthuswamy R, Odunsi K, Edwards RP, Kalinski P. PGE (2)induced CXCL12 production and CXCR4 expression controls the accumulation of human MDSCs in ovarian cancer environment. Cancer Res. 2011;71:7463-70.

71. Guo X, Qiu W, Liu Q, Qian M, Wang S, Zhang Z, Gao X, Chen Z, Xue H, Li G. Immunosuppressive effects of hypoxia-induced glioma exosomes through myeloid-derived suppressor cells via the miR-10a/Rora and miR-21/Pten pathways. Oncogene. 2018;37:4239-59.

72. Chalmin F, Ladoire S, Mignot G, Vincent J, Bruchard M, Remy-Martin JP, Boireau W, Rouleau A, Simon B, Lanneau D, et al. Membrane-associated Hsp72 from tumor-derived exosomes mediates STAT3-dependent immunosuppressive function of mouse and human myeloid-derived suppressor cells. J Clin Invest. 2010;120:457-71.

73. Xiang X, Liu Y, Zhuang X, Zhang S, Michalek S, Taylor DD, Grizzle W, Zhang HG. TLR2-mediated expansion of MDSCs is dependent on the source of tumor exosomes. Am J Pathol. 2010;177:1606-10.

74. Hammerer-Lercher A, Mair J, Bonatti J, Watzka SB, Puschendorf B, Dirnhofer S. Hypoxia induces heat shock protein expression in human coronary artery bypass grafts. Cardiovasc Res. 2001;50:115-24.

75. Stridh L, Smith PL, Naylor AS, Wang X, Mallard C. Regulation of toll-like receptor 1 and -2 in neonatal mice brains after hypoxia-ischemia. J Neuroinflammation. 2011;8:45.

76. Yin $Y$, Cai $X$, Chen $X$, Liang $H$, Zhang $Y$, Li J, Wang Z, Chen $X$, Zhang W, Yokoyama $S$, et al. Tumor-secreted miR-214 induces regulatory T cells: a major link between immune evasion and tumor growth. Cell Res. 2014;24: 1164-80.

77. Yang L, Zhang W, Wang Y, Zou T, Zhang B, Xu Y, Pang T, Hu Q, Chen M, Wang $L$, et al. Hypoxia-induced miR-214 expression promotes tumour cell proliferation and migration by enhancing the Warburg effect in gastric carcinoma cells. Cancer Lett. 2018;414:44-56.

78. Ye SB, Zhang H, Cai TT, Liu YN, Ni JJ, He J, Peng JY, Chen QY, Mo HY, Jun C, et al. Exosomal miR-24-3p impedes T-cell function by targeting FGF11 and serves as a potential prognostic biomarker for nasopharyngeal carcinoma. J Pathol. 2016;240:329-40.

79. Rong L, Li R, Li S, Luo R. Immunosuppression of breast cancer cells mediated by transforming growth factor-beta in exosomes from cancer cells. Oncol Lett. 2016;11:500-4.

80. Muller L, Simms P, Hong CS, Nishimura MI, Jackson EK, Watkins SC, Whiteside TL. Human tumor-derived exosomes (TEX) regulate Treg functions via cell surface signaling rather than uptake mechanisms. Oncoimmunology. 2017;6:e1261243. 
81. Lv LH, Wan YL, Lin Y, Zhang W, Yang M, Li GL, Lin HM, Shang CZ, Chen YJ, Min J. Anticancer drugs cause release of exosomes with heat shock proteins from human hepatocellular carcinoma cells that elicit effective natural killer cell antitumor responses in vitro. J Biol Chem. 2012;287:15874-85.

82. Zech D, Rana S, Buchler MW, Zoller M. Tumor-exosomes and leukocyte activation: an ambivalent crosstalk. Cell Commun Signal. 2012;10:37.

83. Pogge von Strandmann E, Simhadri VR, von Tresckow B, Sasse $S$, Reiners KS, Hansen HP, Rothe A, Boll B, Simhadri VL, Borchmann P, et al. Human leukocyte antigen-B-associated transcript 3 is released from tumor cells and engages the NKp30 receptor on natural killer cells. Immunity. 2007;27:965-74.

84. Berchem G, Noman MZ, Bosseler M, Paggetti J, Baconnais S, Le Cam E, Nanbakhsh A, Moussay E, Mami-Chouaib F, Janji B, Chouaib S. Hypoxic tumor-derived microvesicles negatively regulate NK cell function by a mechanism involving TGF-beta and miR23a transfer. Oncoimmunology. 2016;5:e1062968

85. Paggetti J, Haderk F, Seiffert M, Janji B, Distler U, Ammerlaan W, Kim YJ, Adam J, Lichter P, Solary E, et al. Exosomes released by chronic lymphocytic leukemia cells induce the transition of stromal cells into cancer-associated fibroblasts. Blood. 2015;126:1106-17.

86. Krebsbach PH, Kuznetsov SA, Bianco P, Robey PG. Bone marrow stromal cells: characterization and clinical application. Crit Rev Oral Biol Med. 1999; 10:165-81.

87. Feng $H$, Zhao JK, Schiergens TS, Wang PX, Ou BC, Al-Sayegh R, Li ML, Lu AG, Yin S, Thasler WE. Bone marrow-derived mesenchymal stromal cells promote colorectal cancer cell death under low-dose irradiation. $\mathrm{Br} J$ Cancer. 2018;118:353-65.

88. Ghosh AK, Secreto CR, Knox TR, Ding W, Mukhopadhyay D, Kay NE. Circulating microvesicles in B-cell chronic lymphocytic leukemia can stimulate marrow stromal cells: implications for disease progression. Blood. 2010;115:1755-64.

89. Condeelis J, Pollard JW. Macrophages: obligate partners for tumor cell migration, invasion, and metastasis. Cell. 2006;124:263-6.

90. Zhu Y, Chen X, Pan Q, Wang Y, Su S, Jiang C, Li Y, Xu N, Wu L, Lou X, Liu S. A comprehensive proteomics analysis reveals a secretory path- and statusdependent signature of exosomes released from tumor-associated macrophages. J Proteome Res. 2015;14:4319-31.

91. Yang M, Chen J, Su F, Yu B, Su F, Lin L, Liu Y, Huang JD, Song E. Microvesicles secreted by macrophages shuttle invasion-potentiating microRNAs into breast cancer cells. Mol Cancer. 2011;10:117.

92. Zheng P, Chen L, Yuan X, Luo Q, Liu Y, Xie G, Ma Y, Shen L. Exosomal transfer of tumor-associated macrophage-derived miR-21 confers cisplatin resistance in gastric cancer cells. J Exp Clin Cancer Res. 2017;36:53.

93. Zheng P, Luo Q, Wang W, Li J, Wang T, Wang P, Chen L, Zhang P, Chen H, Liu $Y$, et al. Tumor-associated macrophages-derived exosomes promote the migration of gastric cancer cells by transfer of functional apolipoprotein $E$. Cell Death Dis. 2018;9:434

94. Meloche J, Le Guen M, Potus F, Vinck J, Ranchoux B, Johnson I, Antigny F, Tremblay E, Breuils-Bonnet S, Perros F, et al. miR-223 reverses experimental pulmonary arterial hypertension. Am J Physiol Cell Physiol. 2015;309:C363-72.

95. Zhu GQ, Tang YL, Li L, Zheng M, Jiang J, Li XY, Chen SX, Liang XH. Hypoxia inducible factor 1alpha and hypoxia inducible factor 2alpha play distinct and functionally overlapping roles in oral squamous cell carcinoma. Clin Cancer Res. 2010;16:4732-41.

96. Papi A, Storci G, Guarnieri T, De Carolis S, Bertoni S, Avenia N, Sanguinetti A, Sidoni A, Santini D, Ceccarelli C, et al. Peroxisome proliferator activated receptor-alpha/hypoxia inducible factor-1alpha interplay sustains carbonic anhydrase IX and apoliprotein E expression in breast cancer stem cells. PLoS One. 2013;8:e54968.

97. Fais S. NK cell-released exosomes: natural nanobullets against tumors. Oncoimmunology. 2013;2:e22337.

98. Zhu L, Kalimuthu S, Gangadaran P, Oh JM, Lee HW, Baek SH, Jeong SY, Lee SW, Lee J, Ahn BC. Exosomes derived from natural killer cells exert therapeutic effect in melanoma. Theranostics. 2017;7:2732-45.

99. Lugini L, Cecchetti S, Huber V, Luciani F, Macchia G, Spadaro F, Paris L, Abalsamo L, Colone M, Molinari A, et al. Immune surveillance properties of human NK cell-derived exosomes. J Immunol. 2012;189:2833-42.

100. Baginska J, Viry E, Paggetti J, Medves S, Berchem G, Moussay E, Janji B. The critical role of the tumor microenvironment in shaping natural killer cellmediated anti-tumor immunity. Front Immunol. 2013;4:490.
101. Sarkar S, Germeraad WT, Rouschop KM, Steeghs EM, van Gelder M, Bos GM, Wieten L. Hypoxia induced impairment of NK cell cytotoxicity against multiple myeloma can be overcome by IL-2 activation of the NK cells. PLoS One. 2013;8:e64835.

102. Deep G, Panigrahi GK. Hypoxia-induced signaling promotes prostate Cancer progression: exosomes role as messenger of hypoxic response in tumor microenvironment. Crit Rev Oncog. 2015;20:419-34.

103. Zhao H, Yang L, Baddour J, Achreja A, Bernard V, Moss T, Marini JC, Tudawe T, Seviour EG, San Lucas FA, et al. Tumor microenvironment derived exosomes pleiotropically modulate cancer cell metabolism. Elife. 2016;5:e10250.

104. Au Yeung CL, Co NN, Tsuruga T, Yeung TL, Kwan SY, Leung CS, Li Y, Lu ES, Kwan K, Wong KK, et al. Exosomal transfer of stroma-derived miR21 confers paclitaxel resistance in ovarian cancer cells through targeting APAF1. Nat Commun. 2016;7:11150.

105. Cosme J, Guo H, Hadipour-Lakmehsari S, Emili A, Gramolini AO. Hypoxiainduced changes in the fibroblast Secretome, exosome, and whole-cell proteome using cultured, cardiac-derived cells isolated from neonatal mice. J Proteome Res. 2017;16:2836-47.

106. Wang M, Zhao C, Shi H, Zhang B, Zhang L, Zhang X, Wang S, Wu X, Yang T, Huang $F$, et al. Deregulated microRNAs in gastric cancer tissue-derived mesenchymal stem cells: novel biomarkers and a mechanism for gastric cancer. Br J Cancer. 2014;110:1199-210.

107. Roccaro AM, Sacco A, Maiso P, Azab AK, Tai YT, Reagan M, Azab F, Flores LM, Campigotto F, Weller E, et al. BM mesenchymal stromal cell-derived exosomes facilitate multiple myeloma progression. J Clin Invest. 2013; 123:1542-55.

108. Bliss SA, Sinha G, Sandiford OA, Williams LM, Engelberth DJ, Guiro K, Isenalumhe LL, Greco SJ, Ayer S, Bryan M, et al. Mesenchymal stem cellderived exosomes stimulate cycling quiescence and early breast Cancer dormancy in bone marrow. Cancer Res. 2016;76:5832-44.

109. Pakravan K, Babashah S, Sadeghizadeh M, Mowla SJ, MossahebiMohammadi M, Ataei F, Dana N, Javan M. MicroRNA-100 shuttled by mesenchymal stem cell-derived exosomes suppresses in vitro angiogenesis through modulating the mTOR/HIF-1alpha/NEGF signaling axis in breast cancer cells. Cell Oncol (Dordr). 2017:40:457-70.

110. Fatima F, Nawaz M. Stem cell-derived exosomes: roles in stromal remodeling, tumor progression, and cancer immunotherapy. Chin J Cancer. 2015;34:541-53.

111. Pitt JM, Andre F, Amigorena S, Soria JC, Eggermont A, Kroemer G, Zitvogel L. Dendritic cell-derived exosomes for cancer therapy. J Clin Invest. 2016; 126:1224-32.

112. Montecalvo A, Larregina AT, Shufesky WJ, Stolz DB, Sullivan ML, Karlsson JM, Baty CJ, Gibson GA, Erdos G, Wang Z, et al. Mechanism of transfer of functional microRNAs between mouse dendritic cells via exosomes. Blood. 2012;119:756-66.

113. Viaud S, Terme M, Flament C, Taieb J, Andre F, Novault S, Escudier B, Robert C, Caillat-Zucman S, Tursz T, et al. Dendritic cell-derived exosomes promote natural killer cell activation and proliferation: a role for NKG2D ligands and IL-15Ralpha. PLoS One. 2009;4:e4942.

114. Hao S, Bai O, Yuan J, Qureshi M, Xiang J. Dendritic cell-derived exosomes stimulate stronger CD8+ CTL responses and antitumor immunity than tumor cell-derived exosomes. Cell Mol Immunol. 2006;3:205-11.

115. Kumar V, Gabrilovich DI. Hypoxia-inducible factors in regulation of immune responses in tumour microenvironment. Immunology. 2014;143:512-9.

116. Ismail N, Wang Y, Dakhlallah D, Moldovan L, Agarwal K, Batte K, Shah P, Wisler J, Eubank TD, Tridandapani S, et al. Macrophage microvesicles induce macrophage differentiation and miR-223 transfer. Blood. 2013;121:984-95.

117. Cheng L, Wang Y, Huang L. Exosomes from M1-polarized macrophages potentiate the Cancer vaccine by creating a pro-inflammatory microenvironment in the lymph node. Mol Ther. 2017;25:1665-75.

118. Geis-Asteggiante L, Belew AT, Clements VK, Edwards NJ, Ostrand-Rosenberg S, El-Sayed NM, Fenselau C. Differential content of proteins, mRNAs, and miRNAs suggests that MDSC and their exosomes may mediate distinct immune suppressive functions. J Proteome Res. 2018;17:486-98.

119. Zoller M, Zhao K, Kutlu N, Bauer N, Provaznik J, Hackert T, Schnolzer M. Immunoregulatory effects of myeloid-derived suppressor cell exosomes in mouse model of autoimmune alopecia Areata. Front Immunol. 2018;9:1279.

120. Deng Z, Rong Y, Teng Y, Zhuang X, Samykutty A, Mu J, Zhang L, Cao P, Yan J, Miller D, Zhang HG. Exosomes miR-126a released from MDSC induced by DOX treatment promotes lung metastasis. Oncogene. 2017;36:639-51. 
121. Liu G, Bi Y, Shen B, Yang H, Zhang Y, Wang X, Liu H, Lu Y, Liao J, Chen X, Chu Y. SIRT1 limits the function and fate of myeloid-derived suppressor cells in tumors by orchestrating HIF-1alpha-dependent glycolysis. Cancer Res. 2014;74:727-37.

122. Noman MZ, Desantis G, Janji B, Hasmim M, Karray S, Dessen P, Bronte V, Chouaib S. PD-L1 is a novel direct target of HIF-1alpha, and its blockade under hypoxia enhanced MDSC-mediated T cell activation. J Exp Med. 2014; 211:781-90.

123. Liu W, Chen H, Wong N, Haynes W, Baker CM, Wang X. Pseudohypoxia induced by miR-126 deactivation promotes migration and therapeutic resistance in renal cell carcinoma. Cancer Lett. 2017:394:65-75.

Ready to submit your research? Choose BMC and benefit from:

- fast, convenient online submission

- thorough peer review by experienced researchers in your field

- rapid publication on acceptance

- support for research data, including large and complex data types

- gold Open Access which fosters wider collaboration and increased citations

- maximum visibility for your research: over $100 \mathrm{M}$ website views per year

At BMC, research is always in progress.

Learn more biomedcentral.com/submissions 